In a consideration of the direct matching test before blond transfusion (page 694) the use of albumin is referred to, but the very valuable Coombs' technique is not mentioned. Indeed, it is not quite clear what test is recommended and in what circumstances. The general advice, however, that the work should, wherever possible, be undertaken in a properly-equipped laboratory by an experienced person is clearly sound.

The above criticisms can only be considered as minor blemishes in a work of this size. Without question, the authors are to be congratulated on having carried out a revision of so large a field.

$$
\text { J.V.D. }
$$

\section{OPHTHALMIC MEDICINE}

By J. H. Doggart, M.A., M.D., F.R.C.S. Pp. x +329 ; with 87 illustrations, many in colour. London: J. and A. Churchill. 1949. 32s.

The common ground of ophthalmology and general medical disorders has been adequately explored by few writers and the need for a successor to Foster Moore's classic work has been keenly felt for some time. Mr. Doggart has set out to fill this need and the result is an eminently readable little book of some 35 chapters, pleasantly produced and liberally illustrated.

Space is devoted to ophthalmological manifestations of general infections, disorders of the throat, nose and ear, skin diseases, metabolic, cardiovascular blood and renal disorders and the student may find here a reference, of necessity brief, to the chief ocular manifestations of such diseases. Four excellent introductory chapters deal with ophthalmic symptomatology and methods of examination and these include a particularly well-illustrated section on physical signs, whilst a chapter on the significance of refractive errors has wisely been given a central position in the book. Later chapters deal with the broad relationships of neurological and ophthalmological disorder, congenital abnormalities and the effects of drugs and poisons.

For the physician in training and the physician in practice the book will be found a useful addition to his library.

\section{H.E.H.}

\section{STUDIES ON TUMOUR FORMATION}

By the late G. W. DE P. Nicholson. Pp. $x+637$, with 184 illustrations. London: Butterworth \& Co. 1950. $£ 33$ s.

This volume is a beautifully produced reprint of the late G. W. Nicholson's 20 Studies on Tumour Formation which appeared in Guy's Hospital Reports between 1922 and I938. To Nicholson's contemporaries and students these studies need no commendation, and their reappearance in this compact form will be very welcome. To pathologists of a younger generation, it affords a ready access to the principal works of one of their greatest predecessors, a master of his subject who was not widely enough appreciated in his own lifetime. The 3 Studies cover a wide range-the general structure $\stackrel{\circ}{\circ}$ of tumours, hamartomas and other minor mal- $C$. formations, heterotopia of tissues, metaplasia, $\overrightarrow{\vec{F}}$ endometriosis, mixed tumours and teratomas. On $\stackrel{\mathscr{S}}{\stackrel{9}{ }}$ all of these subjects Nicholson wrote with great 0 originality, with a stronger basis in general biology than any other writer, with arresting and amusing $\frac{\bar{\omega}}{5}$ criticisms of ill-founded hypotheses, and with $\mathbb{\Phi}$ apposite quotations from the classics. In his exposures of the falsity of the hypotheses of Cohn- $ळ$ heim on ' cell rests,' of Grawitz on renal tumours $\overrightarrow{0}$ and of Wilms on teratomas, he was far ahead of most of his contemporaries and indeed of many $\vec{\omega}$ writers of today, who would do well to read him $\stackrel{\circ}{\circ}$ now. Besides containing a wealth of factual infor- 8 mation, Nicholson's Studies are thought-provoking 3 . and piquant, the utterances not only of a great is pathologist, but of a great philosopher and a great biologist. For this reason his work will continue $\mathcal{O}$ to be of permanent interest as a landmark in the history of the subject.

Nicholson's 184 illustrations, most of them microscopical pen-and-ink drawings executed by his own hand, are reproduced here. The original blocks and drawings were not available, so that $\vec{Z}$ the pictures had to be reproduced from the printed $z$ page; the publishers are to be congratulated on the care they have taken to ensure well-nigh perfect 3 reproductions. A full index adds greatly to the $\mathbb{D}$ value of the book, and a glance over this at ong reveals the great range of subjects covered in the 20 Studies.

This volume will be valued, not only "for the wealth of information it contains, but also because it is a worthy memorial to a great pathologist. Guy's Hospital staff, by agreeing to the republication of Nicholson's work in this handy form, have not only fittingly honoured his memory but have also done a signal service to pathology.

\section{R.A.W.}

\section{POSTGRADUATE OBSTETRICS AND GYNAECOLOGY, $195^{\circ}$}

By F. J. Browne, M.D., D.Sc., F.R.C.S.Ed., F.R.C.O.G. Pp. vi +544 , with I07 illustrations. London: Butterworth \& Co., Ltd. 1950. 50s.

This book is largely based upon the author's celebrated postgraduate courses given in recent years at the Soho Hospital for Women, and is written chiefly for those seeking to specialize in obstetrics and gynaecology. In no sense is it a complete textbook, but is a collection of studies selected widely though not altogether at random of from subjects of major practical importance. It $N$ will make a great appeal to ex-Servicemen and to those who, by the lapse of time since their qualifying examinations, have lost touch with advances and current thought; only a great and experienced teacher could have achieved the remarkable blending of fundamentals with up-to-date embellishments with such economy of words and yet such fluent literary style. 
Among many good sections only a few can here be listed, such as the prophylaxis against puerperal sepsis and the technique of barrier nursing, a review of stillbirth and neonatal death, spasmodic dysmenorrhoea and the discussion on anuria and oliguria, but the chapter on venous thrombosis stands out particularly for its wealth of concise and lucid information.

The obstetrical sections are complementary to much that is contained in the author's Ante-natal and Post-natal Care, which explains the absence of chapters, for example, on abortion, pregnancy complicated by diabetes, disproportion and antepartum haemorrhage. Undue prominence appears to have been given to heliotherapy in the treatment of pelvic tuberculosis, and a fuller assessment of conservative versus radical treatment might be given. The use of intravenous ergometrine before delivery of the placenta might be more fully debated for enthusiasm in its use is increasing and its consequent abuse becomes more likely. Isodose curve charts would be welcome in describing radium techniques in the treatment of uterine cancer, and a few more diagrams would be helpful in describing the development of the genital organs. These few minor criticisms are made only in hopeful anticipation of future editions. The book deserves, and will get, an assured place among the standard textbooks of postgraduate study.

I.D.

\section{HISTOLOGY}

By Arthur Worth HaM, M.B. Pp. xix +756 , with $\mathbf{4 4 5}$ illustrations. London : J. B. Lippincott \& Co. 1950. £4.

Dr. Ham is Professor of Histology at Toronto. His previous publications include one in collaboration with a psychologist on the learning problems of medical students, and throughout the book he gives evidence of a real understanding of the student mind, of the simple-seeming problems in visualization that hold up even the brightest and of the profitable discursions into which even the dullest will gladly be drawn. Patiently and thoroughly he progresses through the body, never fearing to pause for explanation or to follow a vein of interesting application, gilding his primary business of descriptive histology but never neglecting it. The result is most impressive. This is not a bock in which to look for minutiae of cytology, but it is remarkably thorough in dealing with many things which are simple enough but lurk somehow in the twilight of most people's knowledge-the relation between microscopic and macroscopic appearance in the skin, the cycle in hair follicles, the build-up of the liver lobule, endochondral ossification (with a really intelligible diagram) and many others.

The pity only is that he takes 756 pages to do it, and that the resultant cost is so high. Whether one could be justified in expecting students in this country to pay so much for a text book of histology is debatable. For its service in illuminating so much of the no man's lard between anatomy and physi- ology it will repay him the light labour of reading $\frac{3}{3}$ it, but much of it will be outside his needs. The $\unrhd$ practising histologist or histopathologist will find $C$ it chiefly of use as a source of ideas in teaching. $\overrightarrow{\vec{F}}$ For the embryo pathologist, who so often finds that $\stackrel{\text { ? }}{+}$ his ignorance of histology is his first and highest hurdle, and to whom the more detailed reference $\bar{\sigma}$ texts are not at first much help, this is the best $\frac{\bar{s}}{T}$ book I know.

B.L.

\section{THE RHESUS DANGER}

By R. N. C. McCurdy, M.B., Ch.B., D.P.H. Pp. 138. London: William Heinemann. 1950. 5s.

For medical men who are naturally chiefly con- $\frac{0}{3}$ cerned with the complex scientific aspects of iso-it immunization, this book is a welcome reminder of $O$ the wider social issues involved. In its. later chapters the author considers the position of the Rh-negative woman who has become immunized against her homozygous $\mathrm{Rh}$ positive husband, and $\overrightarrow{\dot{\partial}}$ who has little chance of giving birth to healthy children. The practice of contraception and the $\frac{}{3}$ wisdom and legal implications of sterilization, abortion, adoption, artificial insemination and $z$ divorce as means of overcoming $\mathrm{Rh}$ incompatibility $\underset{\Phi}{2}$ are all discussed:

Dr. McCurdy quite rightly emphasizes that no final opinion on the above questions can be givea at the present time.

\section{RECENT ADVANCES IN OCULAR PROSTHESIS}

By J. H. Prince, F.B.O.A., F.S.M.C., F.R.M.S., F.Z.S. Pp. viii +155 , with 89 illustrations. Edinburgh: E. \& S. Livingstone Ltd. 1950. 20 .

This small volume supplements the author's 3 previous treatise on the subject with details of improved techniques and newer materials used in making artificial eyes.

Advances in this branch of ophthalmology, since 3 the use of plastics in place of glass has become generally accepted, have concerned, largely, sur- 3 . gical techniques employing a suitable prosthesis to produce a mobile eye of improved appearance. It $\frac{\rho}{3}$ is less surprising, therefore, to find illustrations of surgical procedures in a work of this character $\frac{}{5}$ addressed primarily to technicians.

H.E.H.

\section{WORTH AND CHAVASSE'S SQUINT}

By T. KeITh LYLE, C.B.E., M.A., M.D., M.Chir., N M.R.C.P., F.R.C.S. 8th Edition. Pp. $x+319$, with 208 illustrations. London: Baillière, Tindall and Cox. 1950. 35s.

More than ten years have elapsed since the last edition of this work appeared and a further edition ? has been generally felt to be overdue. In the inter- $T$ val Chavasse's conceptions of the origin of strabis- 